\title{
From Matter to Construction, Sustainable Architecture
}

\author{
By Sara Eriche*
}

\begin{abstract}
The designer always lives the doubt about the possible dichotomy between all that he represents in the project and all that, instead, will actually be realized. The doubt concerns precisely the coherence between the project, L'idée constructive en architecture (Paris: Picard, 1987), to quote the text edited by Xavier Malverti (1954 -), and the construction realized, as the ability to translate an idea represented in constructed object, that is the transformation of an intellectual process into a material object. In this sense, representation translates, defines and transforms the idea of design into graphs and models, while it is the task of the construction to transform and transpose these graphs and models into a building, into architecture. It is therefore a matter of translating a thought drawn into a real object, through a complex path where representation and constructive logic represent central moments of the planning action. And if, as Raphael Moneo (1937 -) writes, a supporter of architecture in which "what precedes is inseparable from what comes later", architecture needs the "support of matter", through a process that accepts, from the beginning, difficulties and compromises, which in reality the subject offers to the one who intends to use it to give completeness and concreteness to an idea, so the construction needs a design thinking that involves all the issues that will be examined during the construction: construction techniques and technologies and then, again, materials, forms and structures. A project that can be built is, in fact, a project in which technical knowledge finds expression in the constructed act, offering design solutions to the intentions of its author. This connection is increasingly narrow in that sector of architecture called "sustainable architecture" where the need for a close liaison, between materials, forms and structures, is stronger; since the relationship between architecture and building technologies, which make such a "sustainable architecture" possible, is expressed through a conscious approach to the construction and the repercussions it has on the surrounding world, according to a timeline that considers the development of time present reciprocally dependent on the future. In this short note, then, we want to present to the benevolent reader a research path in the field of "sustainable architecture" that follows one of the many paths of building with natural materials, or rather with "poor" materials, and show the process that led to the creation of a modest construction in earthstraw with the peculiarity that the supporting structure is entrusted only to the strength of the straw material, associated with the earth material, in a self-construction site assisted in the field of experimentation carried out at the Laboratory of Applied Mechanical Engineering (Lab.MAC) of the School of Architecture of Genoa (Italy).
\end{abstract}

\section{Introduction}

The design act is the tool that allows man to identify, in an imaginative reality, a series of tools that allow him to read, understand and translate ideas and thoughts into an object; an object which, in the will of its creator, can be realized.

${ }^{*} \mathrm{PhD}$ Student, University of Genova, Italy. 
In this phase, design becomes a thought that translates into "sign", a sign that makes it possible to transform an image into reality; and in the planning process this process wants to bring an improvement to the client's requests and made by the designer, through the use of all human faculties that summarize creativity, sensitivity, passion, but also technical-scientific, technological knowledge up to the manuality of the realization. The combination of these capacities represents that quality that distinguishes a good designer from a common architect.

Benedetto Croce (1866 - 1952) clearly expresses the idea of the design act as an indispensable moment of the transition from the idea to the constructed object, be it an object or rather an artifact, a construction: "A system is a house that, soon after built and adorned, needs (subject as it is to the corroding action of the elements) of a work, more or less energetic, but assiduous, of maintenance, and that at a certain moment it is more useful to restore and shore up, and we need to throw it on the ground and rebuild it from its foundations. But with such a capital difference: that, in the work of thought, the perpetually new house is perpetually supported by the ancient, which, almost by magic, lasts in it. As is well known, the masters of this magic, the superficial or naive intellects are frightened; so much so that one of their boring refrains against philosophy is that it continually disrupts his work, and that one philosopher contradicts the other: as if man did not and would always undo and re-make his houses, the next architect he was not the contradictor of the previous architect; and as if from this doing and undoing and redoing houses, and from this contradiction of architects, one could draw the conclusion that it is useless to build houses!" "1

In this Crocian dichotomy of making and undoing, and of the continuous references to the sedimented knowledge of the architect's culture, there is an experience much closer to the art of building than to architectural design, but certainly in line with Croce's thought for which the new is supported by the knowledge of the ancient. The history of the construction, and in particular of the construction of "architectures" of straw, has not yet been written but lives in the collective memory thanks to the experiences of some pioneers ${ }^{2}$ who ventured into a complex and difficult building field where the relationship between form-matterstructure has labile and not perfectly delineated boundaries. Nevertheless, in a line of applied research, which is certainly located in the path of border research, we wanted to look for and follow a path that others, to date, had not yet undertaken. The work that we want to expose in this short note is therefore the synthesis of a path of study and research that led to the construction of the first building with a straw-bearing structure built in Sestri Levante, a small town not far from Genoa. A complex and difficult path, not without obstacles, which required an all-round investigation on the scarce scientific literature, but also and perhaps even more on the existing building, in order to know to understand and, subsequently, transpose this set of knowledge in a project and then in a self-construction site where the

1. Benedetto Croce, Breviario di estetica. Aesthetica in nuce (Milano: Adelphi, 1990), 17-18.

2. Barbara Jones, Costruire con le balle di paglia. Manuale pratico per la progettazione e la costruzione (Firenze: Terra Nuova Edizioni, 2005); Gernot Minke and Friedemann Malke, Maisons en Paille: Techniques, idées et realizations (Chamalières: Artémis, 2009); Eddy Fruchard and Virginie Piaud, Techniques de construction en paille (Paris: Eyrolles, 2015). 
designer-builder relationship was fundamental to reach the desired result.

Documentary research has gone through the narrow fields of specialized literature and then expanded the field of investigation into the vast domain of empirical and experimental research, both on site and in the laboratory, with the aim of acquiring the necessary scientific, technical and technological knowledge, supported by extensive practical experience sedimented on site. This research has allowed us to experiment with innovative technological and design solutions, substantially different from those widespread in current construction practice. The transition from the project to the experimental model was the fundamental act to show on the one hand the simplicity of a construction technique, that in straw and earth, ${ }^{3}$ and on the other the real possibility of success of this technology rich in different declination possibilities, nonetheless complementary to that which envisages the use of mixed construction systems in wood and straw (GREB technique. $)^{4}$

In this process, which has gone through the world of design and that of construction, making them intersect, much attention has been paid to the concept of "environmental sustainability", with the aim of applying one of its different and distinct declinations to architectural design, with the awareness of the great social and moral responsibilities that the architect must have, and by the desire - taking up the thought of Robert Baden-Powell (1857 - 1941) - to "leave the world a little better than we found it."

The constructive system experimented by the Author, with the help of numerous young people who have collaborated on the self-construction building site, does not want to be the optimal "solution" to meet the specific needs of "environmental sustainability" in the broader sense of the term. Vice versa, this experience wants to re-enter, in that domain of applied research that today sees the experimentation of systems, techniques and constructive technologies, using natural or so-called "poor" materials, and is increasingly affecting architects such as Nlè Architects, Diebedo Francis Kerè (1965 -), Shigeru Ban (1957 -), and others. The objective sought and achieved wanted, therefore, to be a magnifying glass on constructions that use straw as a building material, given the increasing diffusion that is found in our days, and provide a constructive example in some innovative ways, possible, concrete and achievable. The project, the study model, the construction site of the full-scale prototype, the tests on the resistance of the materials, the drawing, the photography, the story are the "ingredients" of this work without which it would have been impossible to create this scenario and arrive at the result illustrated in this short note.

\section{A Fleeting Glance at the Concept of Sustainability in Architecture}

For many people the movement of sustainable architecture began in the early

3. Alain Marcom, Construire en terre-paille (Grenoble: Terre Vivante Editions, 2011).

4. Vincent Brossamain and Jean-Baptiste Thévard, Construire son habitation en paille selon la technique du GREB (A Contrevent, 2011).

5. Robert Baden-Powell, Scautismo per ragazzi (Roma: Nuova Fiordaliso, 2003). 
seventies as a response to the oil crisis, for others it began a decade earlier with the publication of the book $^{6}$ by Rachel Carson (1907 - 1964), which for many started the most vast modern environmental movement. Still others believe that the true roots of sustainable architecture can be found much earlier, in the forms of vernacular architecture spread throughout the world ${ }^{7}$. First of all because, as Jason McLennan (1973 -) has pointed out, no "movement" has only one starting point, but the definition of every idea happens thanks to many processes of cause and effect, of action and reaction, of links and connections, which often flow over the centuries; and then because, entering into the specific theme, the appearance of ecology in the debate on "sustainable" architecture, in the sense of "development process tending to harmonize the exploitation of available resources with respect for conditions and compatibility environmental" is based on a historical paradox that has always been present. And that is that architecture exists mainly because it struggles against natural phenomena and, therefore, has always had to deal with the mutability of the different and distinct relationships existing between man and the environment determined by it.

It can therefore be said that the so-called "sustainable architecture", if understood in a broad sense, has had many beginnings and its history can go back more than we can remember. The problem, however, is to understand its historical evolution and to distinguish its meanings in its various declinations over time to understand which is the closest to the theme developed in the self-construction site we will mention. Man has always altered the environment spontaneously using natural resources to create an ideal environmental comfort and originally this phenomenon is associated with the birth and development of vernacular architecture, built with local and "poor" materials: earth, mud, straw, wood, stone. In each region where man took office, vernacular architecture has developed with great attention to the careful use of local natural resources. The development of technologies for the transformation of these resources has subsequently led to the introduction of artificial materials, always derived from natural materials, up to the industrial revolution of the $18^{\text {th }}$ century, where the introduction of machinery that exploited the energy of water before and fossil fuels later, it began processes of transformation of raw materials and the subsequent introduction of artificial materials and derivatives such as cast iron, iron, steel and, at the end of the next century and then at the beginning of the twentieth century, reinforced concrete. In this process of transformation of matter, following the development of industry, a debate on the concept of environmental sustainability began in the twentieth century, following the many problems arising as a result of the exploitation of natural energy sources, primarily fossil fuels, in relation above all to the health of people and to the protection of the environment. Thus there are currents of thought that start the debate on the theme of "sustainable architecture", declined with different facets, aware that establishing a balance between the built environment and the natural environment must and must even today be an objective pursued in the field of transformation anthropic of the territory.

6. Rachel Carson, Silent Spring (Boston: Houghton Mifflin Company, 1962).

7. Paul Oliver, Encyclopedia of Vernacular Architecture of the World (Oxford Brookes University, 1997). 
Already in 1849 Henry David Thoureau (1817 - 1862), amateur naturalist, published the text Resistance to Civil Government ${ }^{8}$ in which, for the first time, it appeared a new sensitivity towards nature that somehow denied the anthropocentric view of the inherent world in Western culture, but anticipated a different relationship between man and nature that will then be declined by the term ecology, introduced by Ernst Haeckel (1834 - 1919), which identifies the theory according to which everything in nature is interconnected. The Haeckelian vision of this new science has certainly contributed to further weaken anthropocentrism, degrading humans to one species among many others and started to exert an evident influence on politics, on the economy, but also on art and on architecture. For example, the organic forms of Art Nouveaux can be interpreted as the artistic correspondent of the scientific illustrations produced by the German scholar, while the Austrian esotericist and theosophist Rudolf Steiner (1861 - 1925), follower and biographer of Haeckel, showed in the first Goetheanum, built entirely of wood from 1913 to 1918, one of the ways to interpret the relationship between organic architecture and ecology: with this architecture "es sollte ein organisch-plastisches Bauen geschaffen werden, das zum formenden Element der Architektur werden sollte." It was certainly not an architecture that worked in a truly ecological way, but it was the symbolic representation of its ecological sympathies, according to an ethical, spiritual and almost religious approach to the ecological question that presented a true form of reverence towards nature and that subsequent decades also appeared in the writings of several architects of the twentieth century.

Despite their dependence on the industrial culture, for example, Frank Lloyd Wright (1867 -1959) and Le Corbusier (1887 - 1965) can be considered both the proto-ecologists, the first with regard to organic architecture and its desire to build "Inside nature", the second to the green city and its desire to build "above nature". To these must certainly be added Richard Neutra (1893 - 1970), probably the first architect to have specifically used the word ecology during a debate on design. In his text, Survival through Design, published in $1953^{10}$ before the advent of the modern environmental movement, the Austrian architect addressed the theme of the relationship between ecology and design, without specifying how to get there and therefore, like Wright and Le Corbusier, a rather negligible influence on the definition of an ecologically aware architecture, even if not yet aware of the declination of "sustainable architecture". Only Paolo Soleri (1919 - 2013), towards the end of the Sixties, resumed the concept of vertical density developed by Le Corbusier to try to give an architectural answer to the ecological movement. But his mega structures completely geographically isolated, like many utopian proposals elaborated in those years such as those of Walter Jonas (1910 - 1979) and Paul Maymont (1926 - 2007), did nothing but recreate those anthropocentric models they thought to oppose. In this sense, therefore, until the end of the Sixties, the influence of the ecological movement within the architectural debates can be

8. Henry David Thoureau, "Resistance to Civil Government," in AEsthetic Papers (ed.) Elizabeth P.Peabody (Boston: The Editor; New York: G.P. Putnam, 1849), 189-211.

9. Hagen Biesantz and Arne Klingborg. Das Goetheanum. Der Bauimpuls Rudolf Steiners (Dornach: Verlag am Goetheanum, 1978), 21.

10. Richard Neutra, Survival through Design (New York: Oxford University Press, 1953). 
considered marginal, thus making the concept of sustainability and its introduction into a very recent architectural context. And perhaps, more recent than we can imagine.

The concept of sustainability was introduced for the first time in 1987 by Gro Harlem Brundtland (1939 -) in the Brundtland report (also known as "Our Common Future") - issued in 1987 by the World Commission on Environment and Development - to indicate a type of economic development that is broadly compatible with social and environmental needs, both in local systems and in its global dimension. In particular, the Norwegian environmental minister introduced the adjective sustainable in all those activities that aim to satisfy human needs: "development that meets the needs of the present without compromising the ability of future generations to meet their own needs".

The concept of sustainable development is therefore strongly linked to the consumption of the quantity of resources - materials and energy - used during the entire life cycle of each product, from its production to final disposal. Therefore, the sustainable project incorporates the concept of sustainability by directing the design act to the definition of an organism that responds, in addition to the morphological-functional values that allow the building to be fully usable, even those criteria related to energy saving and containment environmental impact, the use of recyclable materials, the use of simple technologies. In this way we can try to give a definition of "sustainable architecture", the architecture with low environmental impact, non-invasive, compatible with the environment and the territory, almost completely recyclable and possibly made with natural materials, efficient from the point of energy, based on a conscious use of natural resources, designed and built for the conservation and protection of the territory and the built environment.

In this sense, the construction of the village of Gourna (Kurna), near Luxor in Egypt, built for a community of peasants, designed and built according to the indications of the Egyptian architect Hassan Fathy (1900 - 1989), constitutes a significant example of sustainable project, where priority is the social and cultural well-being of the people and rural self-sufficiency in economic terms. ${ }^{11}$

More recently, a significant experience among those that precede the formalization of the concept of sustainability is The Autarkic House designed and built in the '70s by Alexander Pike (1924-1979), in collaboration with the architecture students of the University of Cambridge, as a model of self-sufficiency, obtained through the use of passive and active solar systems, wind energy and biomass of organic waste. $^{12}$

Today sustainable design is expressed through very different trends that include all those experiences based on the use of elementary and local technologies that can be used in self-construction processes: construction in wood, stone, raw earth (adobe, pisé, torchis, etc.), straw, etc., and favour traditional

11. Hassan Fathy, Architecture for the Poor: An Experiment in Rural Egypt (Chicago: University of Chicago Press, 1976).

12. Dean Hawkes, "Sustainability and architectural synthesis," in Architecture, City, Environment, Proceedings of PLEA 2000: July 2000, Cambridge, United Kingdom (ed.) Koen Steemers and Simos Yannas (London: James and Kames, 2000), 6. 
technologies and participatory construction. ${ }^{13}$ Otherwise, we witness the technological virtuosity aimed at achieving energy savings in relation to the high performance of environmental comfort, to the "ecological humanism", which combines traditional materials, products and innovative technical solutions, the "ecological minimalism", and again to the "eco-minimalism", typical of a new generation of architects and engineers, aimed at a conscious approach to what constitutes a formal and functional project, within which it integrates, often hiding it, the environmental value as that pursued by Carlo Baumschlager (1956 -) and Dietmar Eberle (1952 -) (Baumschlager Eberle Architekten). ${ }^{14}$

\section{Building with Straw: A Participated Self-construction Experience}

The experience that we will briefly show in the following lines was carried out in 2013 in Sestri Levante (Genoa, Italy) as part of the study and research activities carried out by the Laboratory of Applied Mechanical Engineering (Lab.MAC) of the Genoa School of Architecture. The objective pursued and subsequently achieved was that of realizing a modest earth-straw construction, according to the Nebraska method, ${ }^{15}$ where the load-bearing masonry of the construction is made of pre-assembled blocks of straw and tied with ropes in natural fibers. The design and construction process involved the construction of a participated self-construction building site thanks to the commitment of numerous university students, but also of young architects and enthusiasts. The choice of the construction system and the technologies used has favoured the use of natural materials: lime-lime mortars, adobe, pressed straw blocks, earth plasters, wooden roof structures, roof insulation with natural wool, etc. In the context of building, using materials derived from Nature, for example, the load-bearing capacity of pressed straw has enabled the creation of an ideal natural straw building that combines dry construction techniques with those that use natural bedding mortars to base of earth and lime. In a line of research that for some years has seen the revival of models and technologies of the past, building with straw then becomes frontier research that has its archetypes in an almost century-old experimentation. The historic Burke House (Burke House, 1903,) ${ }^{16}$ in the city of Alliance, Nebraska

13. See in this regard the architectures of Lucien Kroll (1927 -) in Belgium, Peter Hübner (1939 -) in Germany and Sverre Fehn (1924 - 2009) in Sweden. 2001).

14. Dominique Gauzin-Müller, L'architecture écologique (La Croix de Berny: Le Moniteur,

15. The first documented use of hay bales used in housing construction dates back to the second half of the nineteenth century in Nebraska. The first construction built was a school, built around 1896 or 1897, without the use of protective plasters. This caused a rapid deterioration of the walls and, in the following years, the builders began to use plasters based on mud, plaster or lime; Jerilou Hammett and Kingsley, "The Strawbale Search," in Designer/builder monthly magazine (August 1998). Between the end of the nineteenth century and the first half of the next century around seventy thatched buildings were built in the Sandhills region: houses, farm buildings, churches, schools, offices and grocery stores; Leanne R. Marks, Straw Bale as a Viable, Cost Effective, and Sustainable Building Material for use in Southeast Ohio (Ohio University, 2005), of which still nine survivors were registered in 1990.

16. Steen Swentzell, Athena, Bill Steen and David Bainbridge, The Straw Bale House (Whie 
or the oldest two-storey house in straw bale (Figure 1), the Maison Feuillette, ${ }^{17}$ built in 1921 in Montargis, France, by engineer Émile Feuillette (c 1873 - 1943) (Figure 2) are the living testimony of a constructive technique and a technology that certainly has ample room for development in the field of applied research of "sustainable architecture.",

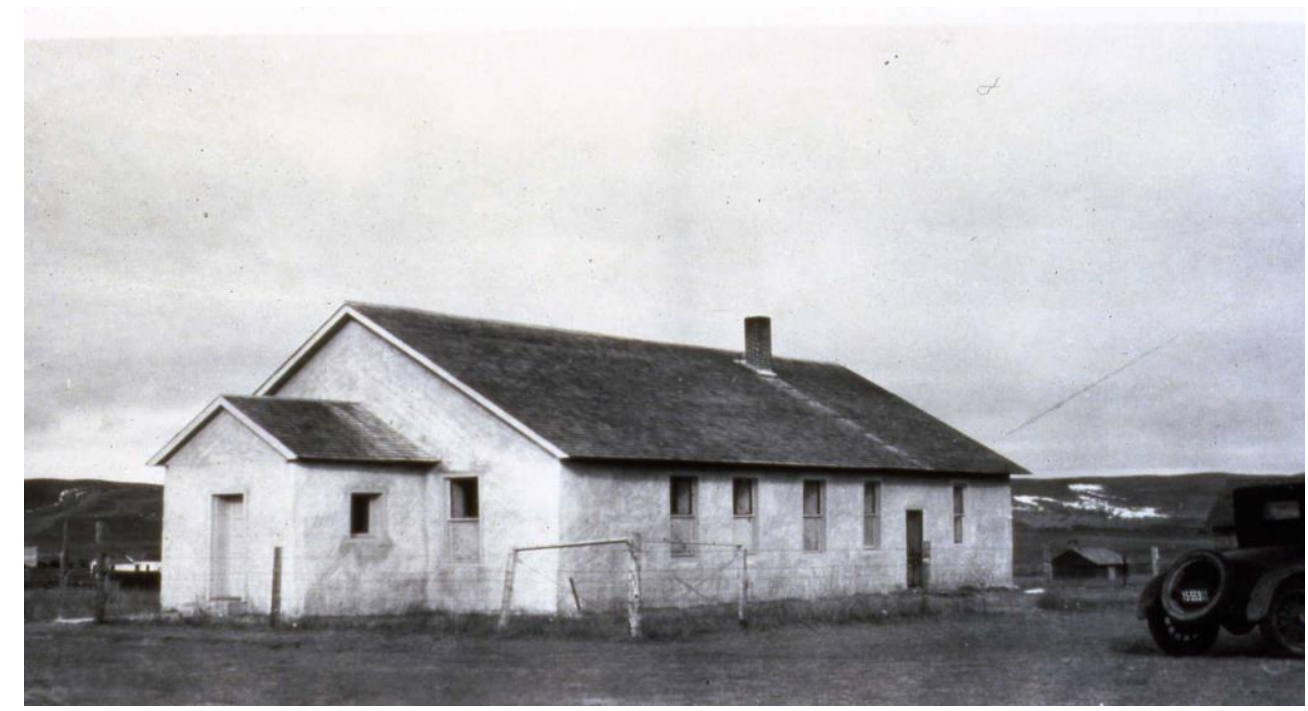

Figure 1. Natural Building in Nebraska, Straw-bale Construction
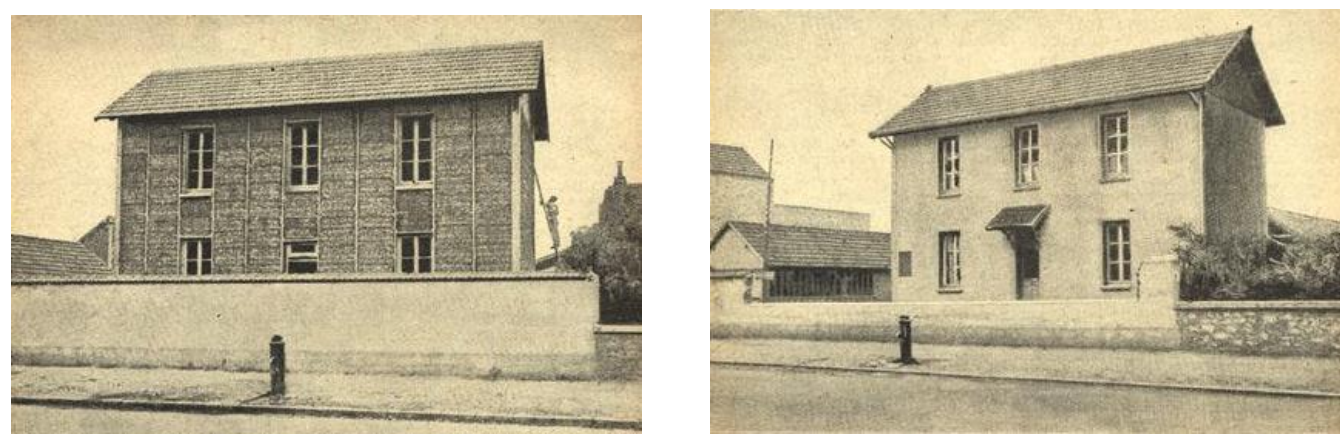

Figure 2. Maison Feuillette, Montargis (France)

The question that then arises is the following: why build with straw? The answer has many variations: because there are performance advantages in terms of thermal insulation, a good load-bearing capacity when associated with wooden structures, resistance to wind and earthquakes, fire resistance but, above all, the

River Junction: Chelsea Green Publishing, 1994), 4-5.

17. Gustave Lamache, "Fraiches en été, chaudes en hiver. Les maisons de paille sont avant tout économiques," in La science et la vie, no. 56 (Mai 1921), 481-86.

18. Astrid Gruber and Herbert, Construire en paille aujourd'hui (Mens: Terre vivante, 2003); Nathaniel Corum, Building a Straw Bale House: The Red Feather construction handbook (New York: Princeton Architectural Press, 2005). Chris Magwood, Peter Mack and Tina Therrien, More Straw Bale Building: A complete guide to designing and building with straw (Gabriola Island, B.C.: New Society Publishers, 2005); André de Bouter, Bâtir en paille. La Maison en Paille, 2006; Bruce King, Design of Straw Bale Buildings: The State of the Art (San Rafael, CA: Green Building Press, 2006); Luc Floissac, La construction en paille (Mens: Terre-vivante, 2012). 
possibility to manage the building site in construction, a fundamental training moment for the knowledge of the architectural construction process. In this sense, the experiences of Hassan Fathy mentioned above are paradigmatic of this line of thought. In the field of building materials derived from natural ones, straw - an inert material with a wood-like chemical composition - suitably pressed into large parallelepipeds, allows the creation of buildings characterized by regular and organic shapes. In this way, the ideal natural straw building becomes a product to be implemented in dry construction techniques that define healthy environments for the inhabitants. In fact, the construction is based on some paradigms that provide for the construction of a wooden bearing structure (GREB) and the construction of walls in juxtaposed parallelepiped blocks made with pressed straw (Nebraska method).

The experience that we will shortly illustrate in this brief note summarizes a cycle of activities that tackle all the basic building techniques of a modest vernacular architecture: from the foundation excavation to the laying of the roof covering. All these activities dealt with the study and methods of use of natural materials, the execution of laboratory tests necessary for the knowledge of the mechanical behaviour of these materials, the techniques and technologies of the construction systems that use these materials and they do not require the use of sophisticated machinery or equipment. The result is the construction of the first straw-bearing structure built in Liguria, where straw was associated with natural materials such as earth, stone, wood and derivatives such as lime. In these terms, this experience is part of a course of study that has as its guideline the culture of environmental sustainability, made its own in the design process and in the construction site. The axonometric cross-section of the straw-bale Construction in Sestri Levante is shown in Figure 3.

All the materials used, and the straw on all, meet all the requirements that must be made of eco-sustainable materials as they are all recyclable and reusable materials, and their reuse allows you to reduce energy costs, thus lowering production costs. Summarizing the construction process can be summarized in the following steps.

- Construction of the masonry foundation: we opted for the creation of a system of direct superficial foundations (maximum depth of the laying surface equal to less than $70 \mathrm{~cm}$ from the ground level) in bricks - double brick curtain wall thickness of two brick heads and internal bag of about $25 \mathrm{~cm}$ width - with mortar-lime, mortar filling with a dosage in parts equal to $65 \%$ sieved earth, $20 \%$ water, $10 \%$ sand and 5\% lime. This lime-lime mortar, with a higher lime content of $7-8 \%$, is been also used for the horizontal and vertical bedding joints of straw blocks. Externally and internally to the masonry of foundation, necessary to isolate the masonry bearing from the ground - since the worst enemy of the straw is water - a gravel drainage of a quarry of different size stratified to the "Roman" is been realized: ${ }^{19}$ with statumen, rudus, nucleus and summa crusta in clay; while internally the nucleus has been replaced by a hornet's nest made with terracotta pots of appropriate size, placed upside down, distributed uniformly and contiguous

19. L. Quilici, "La costruzione delle strade nell'Italia romana," in Ocnus, no. 14 (2006), 157-206. 
among them within the foundation plane with filling in sand, in turn surmounted by a summa crusta in earth-lime mortar (Figure 4). In the perimeter masonry of the foundation, wooden poles were pointed at the top and made impermeable with a coating of pitch, necessary for anchoring the first row of blocks of straw. These posts were then used as vertical connectors to connect the successive rows of blocks of straw juxtaposed and offset from one another.

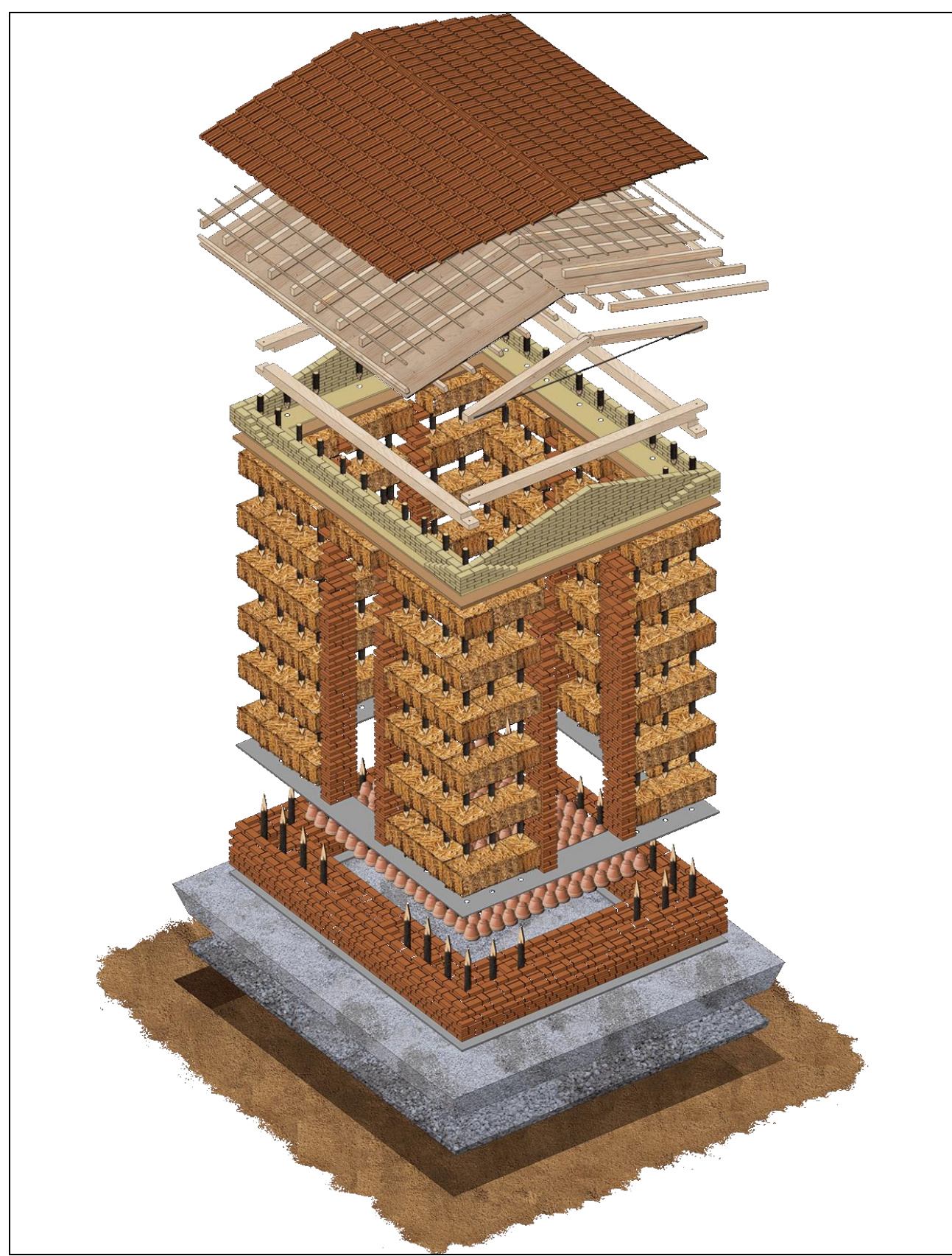

Figure 3. Straw-bale Construction in Sestri Levante (Genoa), Axonometric Crosssection of the Construction 

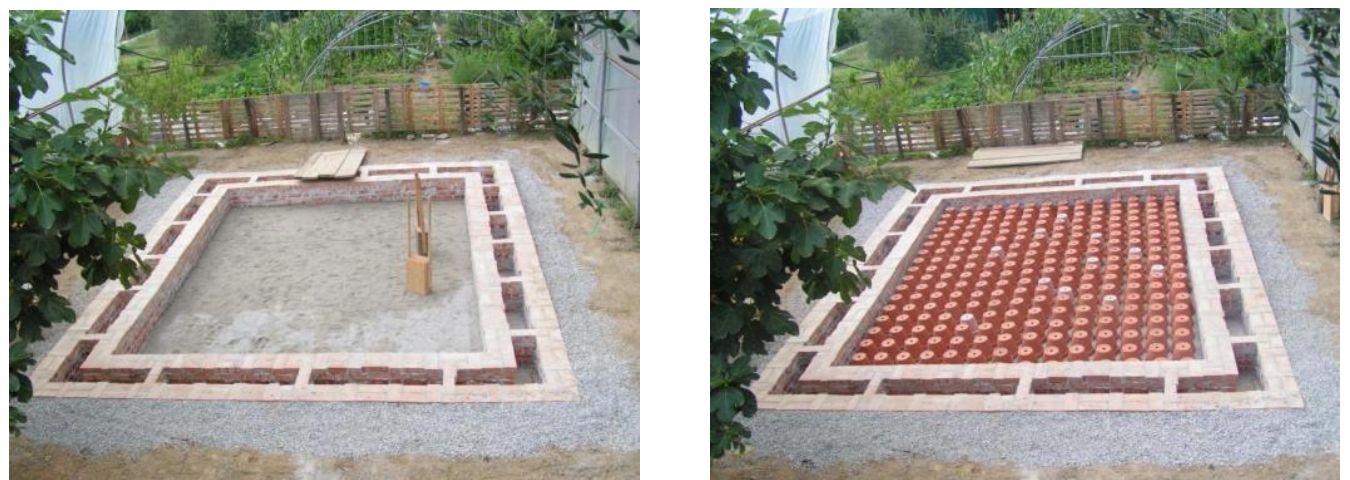

Figure 4. Straw-bale Construction in Sestri Levante (Genoa), Foundation (left), Hornet's Nest (right)

- Construction of the "masonry" box. The straw has been used for the construction of the perimeter walls - $50 \mathrm{~cm}$ thick - with the dual function of supporting structure in elevation and thermal insulation system of the building. The ease of transport and installation of the blocks has shown the validity of the construction system adopted; moreover, the use of lime-lime mortar has favoured the laying of straw blocks and significantly increased the characteristics of resistance to sliding in the horizontal plane and allowed to correct any out of lead of the walls in favour of their stability. An important phase of the construction process was the choice of the straw blocks material, to meet the project requirements. The choice fell on blocks of wheat straw, $50 \mathrm{~cm}$ wide, $40 \mathrm{~cm}$ high and of variable length from $100 \mathrm{~cm}$ to $110 \mathrm{~cm}$, with a weight ranging between 18 and $22 \mathrm{~kg}$ block. The pressed blocks were further pre-compressed with strings in natural fibers. Laboratory tests have shown that such a pre-formed block undergoes a compression deformation of $1 \mathrm{~cm}$ when subjected to a load of $270 \mathrm{~kg}$, equivalent to about $0.05 \mathrm{~kg} / \mathrm{cm}^{2}$
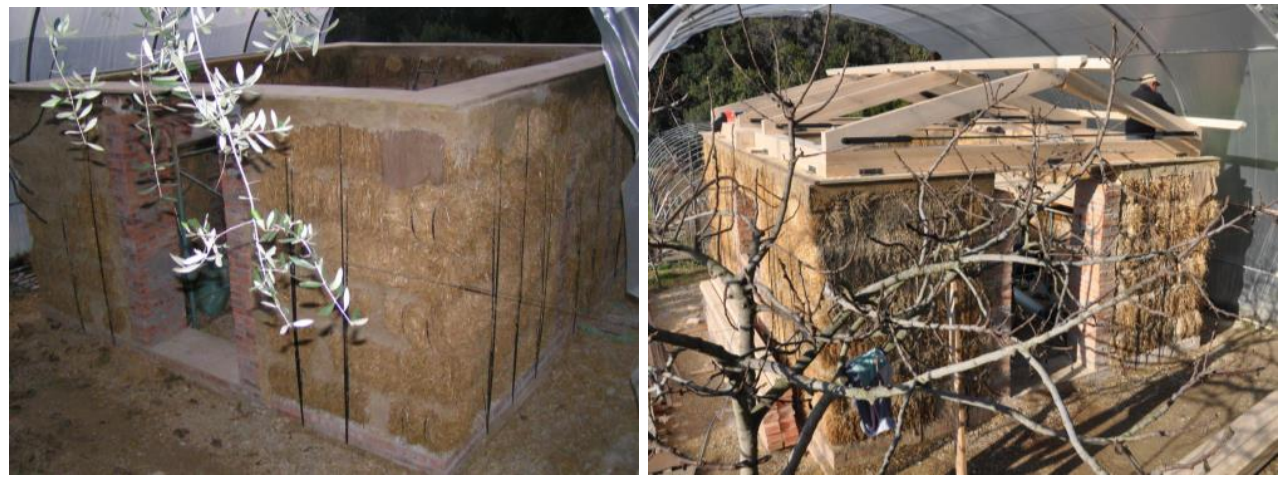

Figure 5. Straw-bale Construction in Sestri Levante (Genoa), Masonry (left), Roof (right)

The method of construction adopted is similar to the Nebraska method, with the addition of a mortar between the blocks of straw as specified above. In this way the masonry of straw blocks supports the roof and there is no need for a timber frame structure to stiffen the box of straw blocks. The straw blocks are arranged in successive rows juxtaposed, moved between them by half block, fixed 
to the foundation are connected to each other by means of chestnut posts appropriately pre-shaped with pointed heads and waterproofed with a pitch layer. In this way, a regular masonry box was created, 4.5 meters by 5.5 meters, with 2.7 meters high walls up to the wooden roof tax floor (Figure 5).

To evenly distribute the weight of the roof on the straw wall, along the entire perimeter of the masonry is disposed a wooden plank of $5 \mathrm{~cm}$ thickness and large as the masonry width, laid on a bed of mortar and anchored by means of vertical pegs in wood to the underlying blocks of straw, in order to obtain a uniform plan and make sure that the weight of the roof generate a uniform compression on the masonry of straw.

- Roof construction and thermal insulation. The structure of the double-pitched roof consists of a system of four pairs of wooden struts, with a hinged connection at the top and a push eliminated by means of iron chains with turnbuckles and resting on a perimetrical sleeper also made of wood. In this way the roof system behaves like a heavy and non-pushing element. The roof (tympani) heads were buffered with adobe masonry at one head. The covering mantle, resting on purlins transverse to the main struts, is formed by a double wooden plank with interposed a layer of sheep wool, washed and not carded, pre-formed in compressed mattresses and the covering mantle is in Marseilles tiles.

- Plasters. The ideal finish for straw is the traditional lime or earth based plaster, and breathable materials, painted with natural paints. The function of limelime plaster, in our case, is to offer adequate protection against rain, humidity and wind. It is important to note that, for the soil-based plaster, numerous very important tests have been performed to evaluate the correct composition of the mixture and its consistency. For all plasters, regardless of the material used as a binder (in this case the lime), the principle that when the plaster is laid, the laying must occur in several layers; these must be progressively thinner from the "slip" to cling to straw, which has a rough and varied surface, up to the final layers of wear. The straw has shown to be an excellent support for the plaster that, after five years from its laying, still shows intact its physical-mechanical and aesthetic characteristics. Doors and windows frames were made with masonry shoulder straps (adobe) and wooden frames.

The entire self-construction process was carried out without the use of special equipment, except for those necessary for the preparation of wooden roof structures, iron chains and their anchorages. In this way it is believed to have created a sustainable, environmentally friendly, reversible and low environmental impact building. The result is an architectural project, albeit modest, but realized with the awareness and the "sensata esperienza" of Galileian memory, in which technical, technological and constructive aspects converge, opportunely used to decline the principles of sustainability in the terms we mentioned in the introduction. The straw-bale construction in Sestri Levante is shown in Figure 6. 


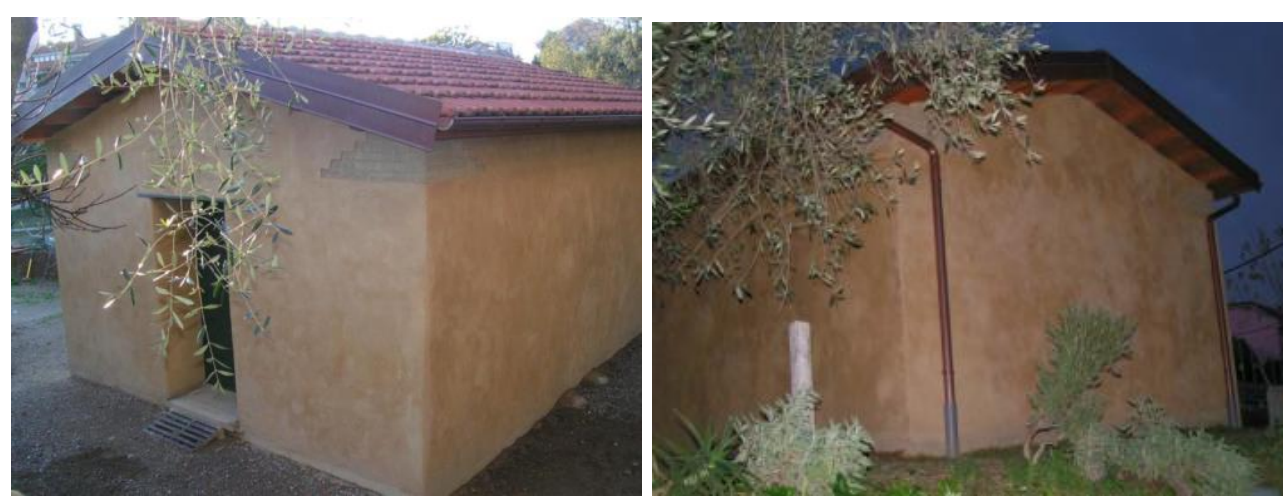

Figure 6. Straw-bale Construction in Sestri Levante (Genoa)

\section{Conclusions}

The history of the construction shows how the process of living from antiquity to today has changed a lot, in the ways, in the forms and in the construction techniques, using from time to time the materials, which the first nature and the industry then put at the disposal of man. In a historical moment where environmental concerns are increasingly taking the field, the research and experimentation of different models of constructions, especially realized with natural materials, makes us understand how in some areas and regions we can opt for solutions that deviate from the common practice of building. The charm of the houses of land, straw or other material that we find in nature, seems to have found a new paradigm of research and shows a modernity that can be overcome, with a long step forward, the concept of the traditional house.

In proposing the earth and straw as a constructive element one should not underestimate an important, though less obvious, aspect of human nature that linked to instinct. Instinct is perhaps the tendency of the man who led him to choose certain materials and to put them together to make their home. The man who first built his house with the land probably built it as a succession of more or less conscious choices, evaluating even bold hypotheses, but discovering the goodness of their choices in successive steps, and learning from mistakes and successes, as we did this self-construction site and how they did or are doing many others around the world by following this line of thought. Today, although the engine that generated the initial hypotheses has now been lost, the documents of those goals remain and it is not easy to find the means to rediscover in us that instinct that led to achieve those results: we must therefore think about we are not as spectators but as privileged actors, still imbued with awareness, although latent, but who can not let every day happen as if we were not the ones who should question the future. In this sense we are the formators of our culture, of the collective sense of places, as well as of the deep meaning of the landscape we inhabit and on which we must act consciously because the culture we know is transmitted to the extent that we understand it and re-evaluate it.

Because of its acceleration, the contemporary world has caused diachronic with the constructions of the past: time and the manner in which we dispose of it 
place us before the observation of the fact that almost never the speed we introduce is the bearer of meaning. Paradoxically, what speed seems to multiply, does not seem to us almost ever up to the meaning of an object built in the past.

The main objective of this research was therefore to respond to a new question: that of a greater demand for housing standards closer to the criteria of eco-sustainability in architecture and building efficiency. We can say that the construction with blocks of straw, together with the use of other natural materials, is possible and very concrete and achievable. We believe that this path represents fully what for us is "sustainable architecture", and those that are the principles on which it is based, and we are sure that this work represents us, hoping to have given rise to curious interest and numerous reflections in the reader on the topic.

\section{Bibliography}

Baden-Powell, Robert. Scautismo per ragazzi [Scouting for children.] (Trad. Ital. di Fausto Catani). Roma: Nuova Fiordaliso, 2003.

Biesantz, Hagen and Arne Klingborg. Das Goetheanum. Der Bauimpuls Rudolf Steiners [The Goetheanum. The construction impulse Rudolf Steiner.] Dornach: Verlag am Goetheanum, 1978.

Bouter, André de. Bâtir en paille. La Maison en Paille [Build straw. The straw house.] 2006.

Brossamain, Vincent et Jean-Baptiste Thévard. Construire son habitation en paille selon la technique du GREB [Build your house in straw according to the technique of GREB.] A Contrevent, 2011.

Carson, Rachel. Silent Spring. Boston: Houghton Mifflin Company, 1962.

Corum, Nathaniel. Building a Straw Bale House: The Red Feather construction handbook. New York: Princeton Architectural Press, 2005.

Croce, Benedetto. Breviario di estetica. Aesthetica in nuce [Breviary of aesthetics. Aesthetica in nuce.] Milano: Adelphi, 1990.

Fathy, Hassan. Architecture for the Poor: An Experiment in Rural Egypt. Chicago: University of Chicago Press, 1976.

Floissac, Luc. La construction en paille [The straw construction.] Mens: Terre-vivante, 2012.

Fruchard, Eddy and Virginie Piaud. Techniques de construction en paille [Straw construction techniques.] Paris: Eyrolles, 2015.

Gauzin-Müller, Dominique. L'architecture écologique [Ecological architecture.] La Croix de Berny: Le Moniteur, 2001.

Gruber, Astrid and Herbert. Construire en paille aujourd'hui [Build straw today.] Mens: Terre vivante, 2003.

Hammett, Jerilou and Kingsley. "The Strawbale Search." In Designer/builder monthly magazine. August 1998.

Hawkes, Dean. "Sustainability and architectural synthesis." In Architecture, City, Environment, Proceedings of PLEA 2000: July 2000, Cambridge, United Kingdom. Edited by Koen Steemers and Simos Yannas. London: James and Kames, 2000.

Jones, Barbara. Costruire con le balle di paglia. Manuale pratico per la progettazione e la costruzione [Build with straw bales. Practical manual for planning and construction.] Firenze: Terra Nuova Edizioni, 2005.

King, Bruce. Design of Straw Bale Buildings: The State of the Art. San Rafael, CA: Green 
Building Press, 2006.

Lamache, Gustave. "Fraiches en été, chaudes en hiver. Les maisons de paille sont avant tout économiques" [Cool in summer, warm in winter. Straw houses are above all economic.] In La science et la vie, no. 56 (May 1921), 481-86.

Magwood, Chris, Peter Mack and Tina Therrien. More Straw Bale Building: A complete guide to designing and building with straw. Gabriola Island, B.C.: New Society Publishers, 2005.

Marcom, Alain. Construire en terre-paille [Build in straw.] Grenoble: Terre Vivante Editions, 2011.

Marks, Leanne R. Straw Bale as a Viable, Cost Effective, and Sustainable Building Material for use in Southeast Ohio. Master's thesis, Ohio University, 2005.

Minke, Gernot and Friedemann Malke. Maisons en Paille: Techniques, idées et realizations [Straw Houses: Techniques, Ideas and Achievements.] Chamalières: Artémis, 2009.

Neutra, Richard. Survival through Design. New York: Oxford University Press, 1953.

Oliver, Paul. Encyclopedia of Vernacular Architecture of the World. Oxford Brookes University, 1997.

Quilici, L. "La costruzione delle strade nell'Italia romana" [Road construction in Roman Italy.] In Ocnus, no. 14 (2006), 157-206.

Swentzell Steen, Athena, Bill Steen and David Bainbridge. The Straw Bale House. Whie River Junction: Chelsea Green Publishing, 1994.

Thoureau, Henry David. "Resistance to Civil Government." In Asthetic Papers. Edited by Elizabeth P.Peabody. Boston: The Editor; New York: G.P. Putnam, 1849, 189-211. 
